\title{
The Association of Metabolic Syndrome with the development of cardiovascular disease among Kazakhs in remote rural areas of Xinjiang, China: a cohort study
}

Wenwen Yang ${ }^{\dagger}$, Shuxia Guo ${ }^{\dagger}$, Haixia Wang, Yu Li, Xianghui Zhang, Yunhua Hu, Heng Guo, Kui Wang, Yizhong Yan, Jingyu Zhang, Jiaolong Ma, Lei Mao, Lati Mu, Jiaming Liu, Yanpeng Song, Changjing Li, Zhuo Ma, Rulin Ma* and Jia He*

\begin{abstract}
Background: Metabolic syndrome (MS) can promote the development of cardiovascular disease (CVD). The objective of this study was to examine the association of MS and its components with CVD, to further prevent and control CVD in Kazakhs.

Methods: In the cohort study, a total of 2644 participants completed the baseline survey between April 2010 and December 2012.The follow-up survey was conducted from April 2016 to December 2016 and was completed by 2286 participants (86.46\% follow-up rate). Cox regression was used to evaluate the association of each component and the number of combinations of MS components on the development of CVD.

Results: A total of 278 CVD patients were enrolled from rural residents of Xinjiang. The average age of the MS and non-MS groups was 46.33 and 38.71 years, respectively. Independent associations with CVD were found for elevated blood pressure (BP) (adjusted hazard ratio (HR) $[\mathrm{aHR}]=1.50,95 \%$ confidence interval $[\mathrm{Cl}]$ : 1.08-2.08), elevated waist circumference (WC) (aHR =1.60, 95\%Cl: 1.19-2.15), and elevated triglycerides (TG) (aHR=1.44, 95\%Cl: 1.04-2.01). Participants with one to 5 MS components had an increased HR for developing CVD, from 1.82to 8.59 (P for trend $<0.001$ ), compared with those with no MS components. The risk of developing CVD increased when TG and WC coexisted (aHR $=2.16,95 \% \mathrm{Cl}: 1.54-3.04)$ ), when TG and BP coexisted ((aHR=1.92, 95\%Cl: 1.32-2.79), and when WC and $\mathrm{BP}$ coexisted $(\mathrm{aHR}=1.93,95 \% \mathrm{Cl}: 1.33-2.82)$ ). However, no significant interactions were found between $\mathrm{BP}, \mathrm{WC}$, and TG.
\end{abstract}

Conclusions: Elevations of BP, WC, and TG were independent risk factors for CVD in Kazakhs. Control of these factors is important to prevent CVD in this population.

Keywords: Metabolic syndrome, Cardiovascular disease, Kazakhs

\footnotetext{
*Correspondence: marulin@126.com; hejia123.shihezi@163.com

†'Wenwen Yang and Shuxia Guo contributed equally to this work.

Department of Public Health, Shihezi University School of Medicine, Shihezi

832000, Xinjiang, China
}

C C The Author(s). 2021 Open Access This article is licensed under a Creative Commons Attribution 4.0 International License, which permits use, sharing, adaptation, distribution and reproduction in any medium or format, as long as you give appropriate credit to the original author(s) and the source, provide a link to the Creative Commons licence, and indicate if changes were made. The images or other third party material in this article are included in the article's Creative Commons licence, unless indicated otherwise in a credit line to the material. If material is not included in the article's Creative Commons licence and your intended use is not permitted by statutory regulation or exceeds the permitted use, you will need to obtain permission directly from the copyright holder. To view a copy of this licence, visit http://creativecommons.org/licenses/by/4.0/ The Creative Commons Public Domain Dedication waiver (http://creativecommons.org/publicdomain/zero/1.0/) applies to the data made available in this article, unless otherwise stated in a credit line to the data. 


\section{Background}

Cardiovascular disease (CVD) has become the leading cause of death in China [1]. Although medical treatments are available for CVD, they are not a lasting solution and the long-term harmful impact of the disease on patient health is challenging to treat. Prevention of CVD is thus an urgent public health issue. However, the underlying cause of CVD is unknown, posing a danger for individuals at high risk of developing the disease.

Metabolic syndrome (MS) is a highly prevalent constellation of vascular risk factors that include elevated blood pressure (BP), elevated blood glucose, obesity, and dyslipidemia [2]. A meta-analysis [3] that included 87 different studies found that MS was associated with an increased risk of CVD (relative risk: 2.35; 95\% confidence interval $[\mathrm{CI}]$ : 2.02-2.73). Several studies have demonstrated the association of MS with CVD among Asian populations in Hong Kong [4], Japan [5], mainland China [6], and Taiwan [7]. However, the differential clustering of MS components and their association with CVD in a Kazakh population in Xinjiang province of China is not clearly understood. Whether this population is most at risk for CVD development in the presence of MS is unclear. Accordingly, there is a need for studies on risk of CVD in the Kazakh population to identify effective methods of disease prevention for these individuals.

Xinjiang, a province in northwestern China, is a multiethnic settlement that includes nomadic Kazakh individuals. Owing to their special ethnicity, living environment, and genetic characteristics, there is a growing double epidemic of dyslipidemia and obesity in Kazakhs [8-10]. To our knowledge, there have been no studies investigating the association of MS with the risks of CVD in the Kazakh population due to the limited public health care resources and poor transportation in the rural regions of Xinjiang. Therefore, the objective of this study was to examine the association of MS and its components with CVD, to further prevent and control the CVD in Kazakhs.

\section{Methods}

\section{Study population}

A four-stage cluster random sampling was used to obtain a representative sample. In the first stage, according to the geographical distribution of the minority populations in Xinjiang, we selected Yili as the representative prefecture. Yili is approximately $4407 \mathrm{~km}$ (2739 miles) from Beijing. Approximately $98 \%$ of the population belong to the Kazakh minority. In the second stage, we randomly selected Xinyuan County from the Yili Prefecture. In the third stage, we randomly selected sex villages from Xinyuan County. In the final stage, we randomly selected residents $\geq 18$ years of age who had resided in their village for at least 12 months. We excluded those with serious illness, unawareness, and unwillingness to cooperate, as well as pregnant women. A total of 2644 participants completed the baseline survey between April 2010 and December 2012. To improve the rate of follow-up, subjects were interviewed in-person and in household surveys. The follow-up survey was conducted from April 2016 to December 2016. The follow-up rate of $86.46 \%$ (2286 of the 2644 participants). The median follow-up period was 5.49 person-years (in total 11, 014.92 person-years). We then excluded 281 participants who had a history of CVD including coronary heart disease (CHD), stroke, and hypertension at baseline. Thus, as of December 2016, 2005 participants were eligible for the final analyses. Within the follow-up period, a total of 278 individuals developed (Fig. 1). The person-years were calculated as the sum of the individual follow-up times until the occurrence of a CVD incident or the end of 2016.

\section{Epidemiological survey and biochemical analyses}

All subjects completed a demographic information survey during face-to-face interviews. Detailed information about diet, drinking, details of existing disease, and family history of disease was collected by trained investigators. Trained staff measured weight, height, waist circumference (WC), and BP according to standard methods [11]. Blood samples were drawn from the cubital vein into tubes containing heparin sodium in the morning after an 8-h fast. Blood samples were cryopreserved before being transported. Fasting plasma glucose (FPG), triglyceride (TG), and high density lipoprotein cholesterol (HDL-C) levels were measured using a biochemical auto-analyzer (Olympus AU 2700; Olympus Diagnostics, Hamburg, Germany) in the clinical laboratory of the First Affiliated Hospital of Shihezi University School of Medicine. All described methods were performed according to the approved guidelines and regulations. All participants signed informed consent forms before joining the study. This study was approved by the Institutional Ethics Review Board (IERB) of the First Affiliated Hospital of Shihezi University School of Medicine (IERB No.:SHZ2010LL01).

\section{Diagnostic criteria for CVD}

Participants who had first-ever occurrence of stroke (ischemic or hemorrhagic), CHD, or hypertension during the follow-up period were diagnosed as having CVD. Subjects with CHD were hospitalized during the follow-up period if coronary intervention (cardiac catheterization or coronary bypass surgery) was performed, if there was angina (or nitroglycerin was initiated after cohort study), if myocardial infarction 


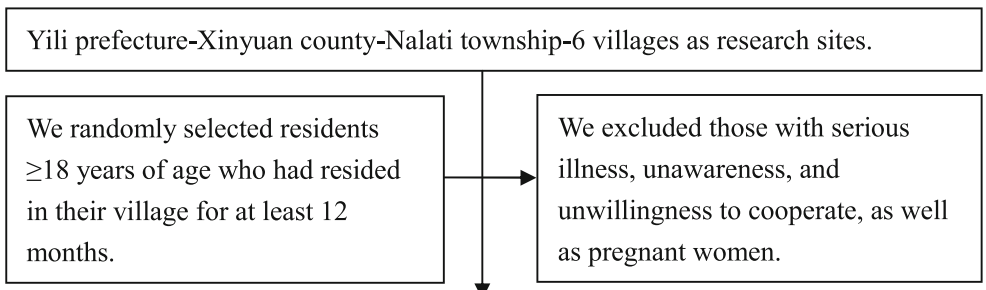

A total of 2,644 participants completed the baseline survey between April 2010 and December 2012 .

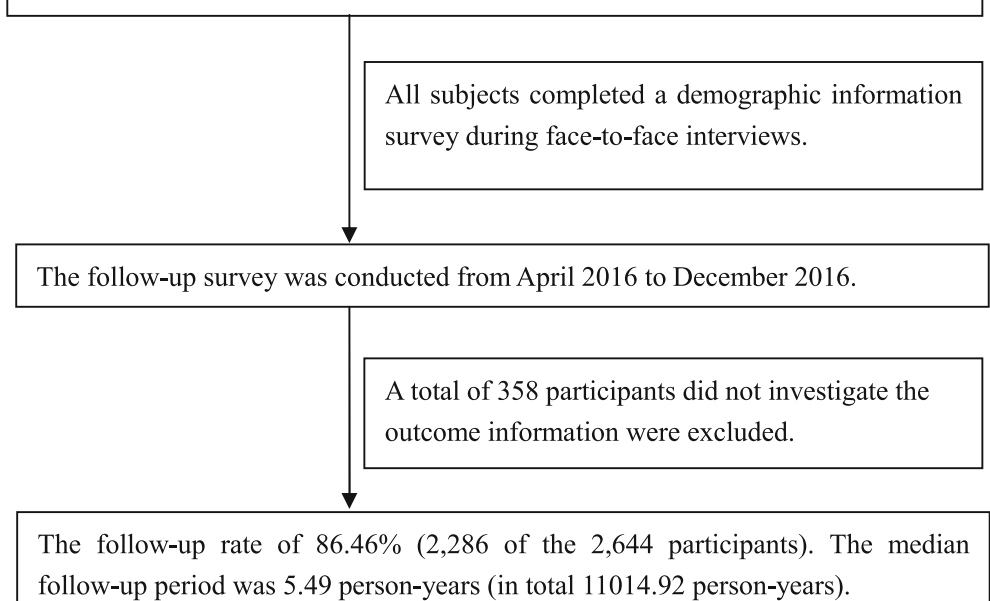
follow-up period was 5.49 person-years (in total 11014.92 person-years).

We then excluded 281 participants who had a history of CVD including coronary heart disease (CHD), stroke, and hypertension at baseline) or lack of information at baseline.

Thus, as of December 2016, 2,005 participants were eligible for the final analyses.

If the same type of CVD event occurred two or more times, the first occurrence was considered as the end event.

Within the follow-up period, a total of 278 individuals developed CVD.

Fig. 1 Flowchart of the study

occurred, and because of congestive heart failure. Data regarding CVD events were obtained from the hospital medical records and questionnaire responses. If the same type of event occurred two or more times, the first occurrence was considered as the end event. CVD were determined based on self-reported questionnaire responses, medical insurance records, and local hospital discharge records from 2010 to 2016. Patients with self-reported manifestations of CVD findings required a certificate of diagnosis from a medical institution in their township during the investigation.

\section{Definition of MS}

According to the third report describing treatment of adult Americans as part of a modified United States National Cholesterol Education Program (2005 NCEP-ATP III) [2].MS is defined when three or more factors are met. These factors include: (1) central obesity: WC $\geq 90$ $\mathrm{cm}$ for men and $\geq 80 \mathrm{~cm}$ for women; (2) elevated TG level $\geq 150 \mathrm{mg} / \mathrm{dL}(1.70 \mathrm{mmol} / \mathrm{L})$; (3) reduced HDL-C < $40 \mathrm{mg} / \mathrm{dL}(1.03 \mathrm{mmol} / \mathrm{L})$ for men and $<50 \mathrm{mg} / \mathrm{dL}(1.30$ $\mathrm{mmol} / \mathrm{L}$ ) for women; (4) elevated $\mathrm{BP} \geq 130 / 85 \mathrm{mmHg}$, or have received the appropriate treatment for hypertension or had been previously diagnosed with hypertension; 
Table 1 Baseline general characteristics of subjects

\begin{tabular}{llll}
\hline Risk factor & MS & Non-MS & $P$ \\
\hline Sex, female / male & $330 / 198$ & $847 / 630$ & 0.039 \\
Age, years & $46.33 \pm 12.04$ & $38.71 \pm 11.83$ & $<0.001$ \\
WC, cm & $91.24 \pm 10.67$ & $79.40 \pm 9.36$ & $<.001$ \\
SBP, $\mathrm{mmHg}$ & $135.74 \pm 18.78$ & $122.97 \pm 17.95$ & $<0.001$ \\
$\mathrm{DBP}, \mathrm{mmHg}$ & $87.42 \pm 12.91$ & $78.71 \pm 11.94$ & $<0.001$ \\
$\mathrm{HDL}-\mathrm{C}, \mathrm{mmol} / \mathrm{L}$ & $1.21 \pm 0.38$ & $1.41 \pm 0.54$ & $<0.001$ \\
$\mathrm{TG}, \mathrm{mmol} / \mathrm{L}$ & $1.79 \pm 1.56$ & $1.06 \pm 0.96$ & $<0.001$ \\
FPG, mmol / L & $5.75 \pm 1.66$ & $5.01 \pm 0.93$ & $<0.001$ \\
Smoking rate, $n$ (\%) & $195(36.93)$ & $434(29.38)$ & 0.001 \\
Drinking rate, $n$ (\%) & $80(15.15)$ & $147(9.95)$ & 0.001 \\
Family history of hypertension, $n(\%)$ & $206(39.02)$ & $501(33.92)$ & 0.035 \\
Family history of diabetes, $n$ (\%) & $9(1.70)$ & $9(0.61)$ & 0.022 \\
Family history of CVD, $n$ (\%) & $56(10.61)$ & $113(7.65)$ & 0.036 \\
Incidence of CVD, $n$ (\%) & $114(21.59)$ & $164(11.10)$ & $<0.001$ \\
\hline
\end{tabular}

WC waist circumference, SBP systolic blood pressure, DBP diastolic blood pressure, HDL-C high-density lipoprotein cholesterol, TG triglyceride, FPG fasting plasma glucose, MS metabolic syndrome, CVD cardiovascular diseases

and (5) elevated FPG $\geq 100 \mathrm{mg} / \mathrm{dL}(5.6 \mathrm{mmol} / \mathrm{L}$ ) or had received appropriate treatment for diabets or had been previously diagnosed with type 2 diabetes.

\section{Confounding factors}

Traditional risk factors used in the data analysis included age, sex, drinking (drinker/non-drinker), and family history of hypertension, diabetes, and CVD.

\section{Statistical analyses}

The database construction and some statistical analyses have been previously described [12]. Cox proportional hazards regression model was used to evaluate the association of each component and the number of combinations of MS components on the development of CVD. Next, we evaluated the interactions between TG and $\mathrm{WC}, \mathrm{TG}$ and $\mathrm{BP}, \mathrm{WC}$ and $\mathrm{BP}$. The grouping method and additive interactions have been previously described [12]. Multiplicative interactions among BP, WC, and TG were evaluated by incorporation of the dummy variable into a Cox regression model. All statistical analyses were performed using SPSS version 17.0 for Windows (SPSS Inc., Chicago, IL,USA). All statistical tests were twosided, and $P<0.05$ was considered statistically significant.

\section{Results}

\section{Baseline characteristics of subjects}

Table 1summarizes the baseline characteristics. In this study, 2286 people completed the follow-up and the median follow-up period was 5.49 person-years (in total 11, 014.92 person-years). During the follow-up,278 who had their first CVD event were identified. The average age of the MS and non-MS groups was 46.33 and 38.71 years, respectively. There were 330 females and 198males in the MS group, and847 females and 630males in the nonMS group. The prevalence of MS was $23.10 \%$ (528/ 2286). Those with MS were significantly older and had higher WC, systolic BP, diastolic BP, TG, and FPG than those without MS. Prevalence of smoking and drinking was significantly higher in the MS group than in the non-MS group (Table 1).

\section{Adjusted hazard ratio (aHR) for CVD and MS with its components in cox proportion hazard regression model} As was expected, MS and the individual components of MS were significantly associated with the risk of developing CVD, independent of age, sex, drinking, and family history of hypertension, diabetes, and CVD. After adjusting for four other MS components and the traditional risk factors above, the elevated BP (aHR 1.50; 95\% CI: 1.08-2.08), elevated WC (aHR 1.60; 95\% CI: 1.19-2.15) and elevated TG (aHR 1.44; 95\% CI: 1.04-2.01) were still independently associated with CVD (Table 2).

\section{aHR of number of MS components associated with CVD}

In contrast with the participants with no MS components, the incidence of CVD was increased with the increase in the number of abnormal components of MS, ranging from 5.56 to $37.50 \%$.Participants with one to five MS components had an increased HR for developing CVD, from 1.82 (95\%CI: $1.07-3.11$ ) to 8.59 (95\%CI:4.43-16.67) (trend $P<0.001$ ), compared to those with no MS components. This trend persisted even after adjusting for age, sex, drinking, and 
Table 2 Adjusted HR for CVD and MS with its components in Cox proportion hazard regression model

\begin{tabular}{llllll}
\hline $\begin{array}{l}\text { Risk } \\
\text { factor }\end{array}$ & $\begin{array}{l}\text { Population } \\
\text { exposure } \\
\text { ratio, (\%) }\end{array}$ & $\begin{array}{l}\text { Incidence } \\
\text { of CVD, (\%) }\end{array}$ & $\begin{array}{l}\text { HR } \\
(\mathbf{9 5} \% \mathbf{C l})^{\mathbf{a}}\end{array}$ & $\begin{array}{l}\text { aHR } \\
\mathbf{( 9 5 \% C l )}^{\mathbf{b}}\end{array}$ & $\begin{array}{l}\text { aHR } \\
\mathbf{( 9 5 \% C l}^{\mathbf{c}}\end{array}$ \\
\hline MS & 26.33 & 21.59 & 2.22 & 1.46 & \\
& & & $(1.75-2.83)$ & $(1.14-1.87)$ & \\
WC & 43.99 & 20.07 & 2.28 & 1.59 & 1.60 \\
& & & $(1.78-2.91)$ & $(1.23-2.05)$ & $(1.19-2.15)$ \\
BP & 45.89 & 19.57 & 2.07 & 1.49 & 1.50 \\
& & & $(1.61-2.64)$ & $(1.11-2.00)$ & $(1.08-2.08)$ \\
TG & 19.75 & 18.69 & 1.78 & 1.55 & 1.44 \\
& & & $(1.36-2.32)$ & $(1.19-2.03)$ & $(1.04-2.01)$ \\
FPG & 28.08 & 16.70 & 1.33 & 1.07 & 1.14 \\
& & & $(1.04-1.70)$ & $(0.83-1.38)$ & $(0.86-1.53)$ \\
HDL-C & 40.00 & 15.09 & 1.48 & 1.36 & 1.34 \\
& & & $(1.17-1.88)$ & $(1.07-1.74)$ & $(0.99-1.82)$ \\
\hline
\end{tabular}

$H R$ hazard ratio, ${ }^{a}$ univariate analysis; ${ }^{b}$ adjusted for age, sex, drinking, and family history of hypertension, diabetes, and $C V D^{c}$ adjusted for four other MS components and the age, sex, drinking, and family history of hypertension, diabetes, and CVD.

family history of hypertension, diabetes, and CVD (Table 3).

\section{Analysis of interactions between BP, WC and TG associated with CVD}

We evaluated the effect of the interaction between WC and TG on CVD development. These two separate factors, arranged into four different subgroups according to their individual absence or presence, were analyzed in pairs by a Cox regression model. Relative to the subgroup without TG and without $\mathrm{WC}$, the HRs associated with CVD were 1.45 (95\% CI: 1.08-1.94), 1.27 (95\% CI: $0.74-2.21$ ), and 2.16 (95\% CI: $1.54-3.04$ ) for the subgroups without TG and with WC, with TG and without

Table 3 Adjusted HR of number of MS components associated with CVD

\begin{tabular}{|c|c|c|c|c|}
\hline & $\begin{array}{l}\text { CVD } \\
\text { (n) }\end{array}$ & $\begin{array}{l}\text { Incidence } \\
\text { of CVD, (\%) }\end{array}$ & $\mathrm{HR}(95 \% \mathrm{Cl})$ & $\begin{array}{l}\mathrm{aHR}^{* *} \\
(95 \% \mathrm{Cl})\end{array}$ \\
\hline 0 component & 17 & 5.56 & $\begin{array}{l}1.00 \\
\text { (reference) }\end{array}$ & $\begin{array}{l}1.00 \\
\text { (reference) }\end{array}$ \\
\hline 1 component* & 62 & 10.25 & $\begin{array}{l}1.82 \\
(1.07-3.11)\end{array}$ & $\begin{array}{l}1.49 \\
(0.87-2.55)\end{array}$ \\
\hline $\begin{array}{l}2 \\
\text { components* }\end{array}$ & 85 & 15.02 & $\begin{array}{l}2.86 \\
(1.70-4.82)\end{array}$ & $\begin{array}{l}1.76 \\
(1.03-2.99)\end{array}$ \\
\hline $\begin{array}{l}3 \\
\text { components* }\end{array}$ & 60 & 17.96 & $\begin{array}{l}3.58 \\
(2.09-6.13)\end{array}$ & $\begin{array}{l}1.89 \\
(1.08-3.29)\end{array}$ \\
\hline $\begin{array}{l}4 \\
\text { components* }\end{array}$ & 36 & 24.66 & $\begin{array}{l}5.68 \\
(3.19-10.12)\end{array}$ & $\begin{array}{l}2.56 \\
(1.41-4.65)\end{array}$ \\
\hline $\begin{array}{l}5 \\
\text { components* }\end{array}$ & 18 & 37.50 & $\begin{array}{l}8.59 \\
(4.43-16.67)\end{array}$ & $\begin{array}{l}4.25 \\
(2.16-8.39)\end{array}$ \\
\hline$P$ for trend & & & $<0.001$ & $<0.001$ \\
\hline
\end{tabular}

${ }^{*}$ Compared with those with 0 components of MS; HR, univariate analysis; **adjusted for age, sex, drinking, and family history of hypertension, diabetes, and CVD; Abbreviations are defined in Tables 1 and 2
Table 4 Multiplicativeinteractions analysis among BP, WC, and TG associated with CVD

\begin{tabular}{lllll}
\hline Factor1 & Factor2 & CVD $(\boldsymbol{n})$ & Incidence of CVD, (\%) & aHR (95\%Cl) \\
\hline WC & TG & & & \\
+ & + & 59 & 23.79 & $2.16(1.54-3.04)$ \\
+ & - & 118 & 18.61 & $1.45(1.08-1.94)$ \\
- & + & 15 & 10.14 & $1.27(0.74-2.21)$ \\
- & - & 86 & 8.82 & 1.00 (reference) \\
BP & TG & & & \\
+ & + & 52 & 25.00 & $1.92(1.32-2.79)$ \\
+ & - & 128 & 17.98 & $1.22(0.90-1.66)$ \\
- & + & 22 & 11.70 & $1.49(0.93-2.40)$ \\
- & - & 76 & 8.47 & $1.00($ reference) \\
BP & WC & & & $1.93(1.33-2.82)$ \\
+ & + & 122 & 24.90 & $1.40(0.93-2.11)$ \\
+ & - & 55 & 14.03 & $1.86(1.24-2.79)$ \\
- & + & 58 & 13.49 & 1.00 (reference) \\
- & - & 43 & 6.20 &
\end{tabular}

aHR adjusted for age, sex, drinking, family history of hypertension, diabetes, and CVD; Abbreviations are defined in Tables 1 and 2.

WC, and with TG and WC, respectively (Table 4). Moreover, with regard to the indexes of additive interaction, the RERI value was 0.53 (95\% CI, $-0.40-1.46)$, AP was $0.25(95 \% \mathrm{CI},-0.15-0.65)$ and SI was $1.91(95 \% \mathrm{CI}$, $0.47-7.70$ ), which indicated no additive interaction between the two risk factors. Interaction analysis between TG or WC and BP on CVD development revealed no additive interactions (Table 5).

\section{Discussion}

Numerous studies have suggested that MS is a cluster of CVD risk factors [13-16]. A meta-analysis [3] that included 87 different studies found that MS was associated with an increased risk of CVD (relative risk: 2.35; 95\% CI: 2.02-2.73). The predictive value of MS and its contribution to CVD should be ascertained in regionspecific populations [17], considering that its effects have been studied in select populations [18]. This study involved Kazakhs. The dietary of this ethnic group is similar, and there is not much variation. They eat pasta and drink milk tea every day. And they don't intermarry with other ethnic groups, so their eating habits remain unchanged. Their special ethnicity, living environment, and genetic characteristics contribute to the higher prevalence of MS and related diseases in Kazakhs than in other ethnic groups [8-10]. However, there are scant longitudinal data regarding the predictive value of MS in the Kazakh population. In this study, MS was associated with CVD in Kazakh subjects. The increased risks of CVD remained significant after adjusting for general risk factors. These findings were also reported in some 
Table 5 Additive interactions among BP, WC, and TG

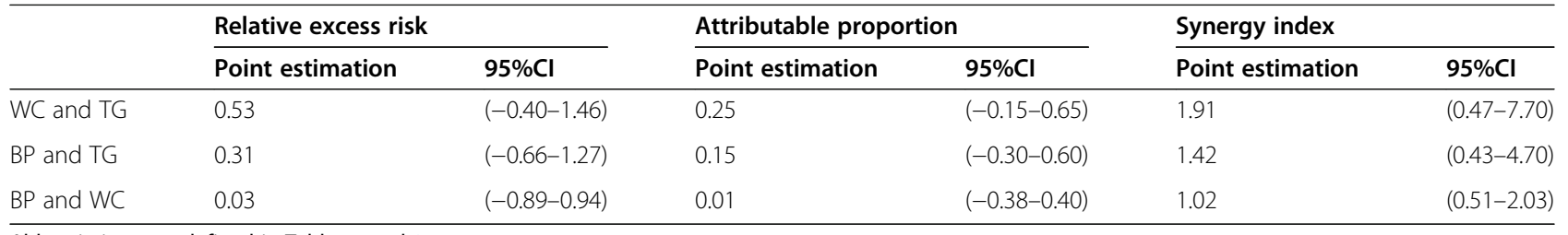

Abbreviations are defined in Tables 1 and 2.

earlier studies [19-22]. These results imply a significant role of MS in the development of CVD in this population. However, another study did not find a no significant correlation between MS and CVD in a biracial cohort of Whites and Blacks, even after adjusting for risks associated with MS components [23]. This finding was also highlighted in the West of Scotland Coronary Prevention Study [24]. These discrepancies may be explained in part by the different MS definitions used and the prevalence of individual components of MS in the studied populations.

Presently, each component of MS appeared to be was associated with an increased prospective risk of CVD. Furthermore, as the number of MS components increased, the risk of CVD also increased, with a significant and cumulative-component response trend. These findings suggest the presence of a cumulative effect of MS components in the elevated risk of CVD. These are important findings because the relationships between clustering patterns of MS and CVD risk have not been thoroughly characterized in Kazakh populations. This synergistic association is also noteworthy as it provides valuable information for the establishment of appropriate policies in preventive CVD for the inhabitants of Xinjiang. This linear synergistic correlation has been previously reported in other ethnic groups [21, 22].

The independent association of MS and its components in predicting CVD has become a subject of recent research interest. However, which MS component is more strongly associated with CVD remains unclear. In the Asia Pacific region, up to $66 \%$ of some subtypes of CVD can be attributed to hypertension [25]. A more important role for BP than other components in determining cardiovascular events has been indicated in several studies [26, 27]. Likewise, after adjusting for four other MS components as well as general risk factors, BP remained independently associated with increased risks of CVD in the Kazakh population. The collective data indicate that elevated BP is an independent risk factor for the development of CVD.

Current research found the elevations of BP, WC, and TG were independent risk factors for CVD in the Kazakh population. Suh et al. [16] found that BP and abdominal obesity were key predictors of CVD in Koreans when adjusting for general risk factors and MS components. For subjects in the National Health and Nutrition Examination Survey III, BP and HDL-C were associated with CHD when adjusted for general risk factors and MS components [28]. Hadaegh et al. [29] studied Middle-East Caucasian residents in Tehrani and highlighted that the FPG level in women and WC in men were independently associated with CVD. These reports are inconsistent in terms of the MS components that predict CVD. These discrepancies may be explained in part by the different study populations, follow-up periods, MS definition used, and prevalence of individual components of MS in different populations.

Hypertension is a risk factor for the development of atherosclerosis. Both clinical and experimental data show that elevated BP enhances the development of atherosclerosis. In fact, atherosclerosis tends to occur only in those parts of the vascular system subjected to high pressure [30]. The elevated TG levels are independently associated with an increased risk of CVD [31]. Elevated blood levels of triglyceride remnants have been linked to the progression of CVD by directly contributing to atherosclerotic plaque formation and progression $[32,33]$. Both BMI and WC are strongly correlated with total body adipose tissue mass with a correlation coefficient $(\mathrm{r})>0.80$ [34]. The $\mathrm{WC}$ is a better correlate of intraabdominal adipose tissue $(\mathrm{r}=0.77-0.79)$ than BMI $(\mathrm{r}=$ 0.59-0.69) [34]. Adipose tissue functions as an endocrine organ by secreting multiple immune-modulatory proteins known as adipokines. Obesity leads to increased expression of pro-inflammatory adipokines and diminished expression of anti-inflammatory adipokines, resulting in the development of a chronic low- grade inflammatory state. This adipokine imbalance is thought to be a key event in promoting both systemic metabolic dysfunction and cardiovascular disease [35].

We analyzed further the interaction between TG and WC or between WC / TG and BP and explored whether their coexistence was an additional risk factor for CVD. When TG and WC coexisted, the aHR was 2.16 , which indicated that the accumulation of TG and WC strengthens the CVD risk. Therefore, it is plausible that the coexistence of TG and WC constitutes the highest CVD risk. If so, the growing double epidemic of obesity and dyslipidemia among Kazakh people may greatly and rapidly increase their burden of developing CVD. 
Therefore, the dietary intervention play an important role in decreasing the incidence of CVD and improving the quality of life in the Kazakh population.

\section{Study limitations}

This study is a large-scale prospective cohort study of a Kazakh population with a long follow-up period that reports the association of MS with CVD incidence. Our study had some limitations. First, the diagnosis of MS was based on a single measurement of its components at baseline, as was the case in other epidemiological studies [36]. Second, because of site-specific limitations, the CVD outcomes analyzed here failed to include hospitalization or outpatient visits due to a transient myocardial ischemia that prevented symptom remission, which may have led to the underestimation of CVD incidence. Third, Kazakh is a large nomadic nation in Xinjiang and the fluidity is relatively large, physical activity was not assessed and therefore not accounted for in the multivariate model. Despite the limitations, our findings may be generalized to populations residing in lowincome rural areas of Xinjiang. In addition, our findings may provide some important insights regarding issues related to the relationship between MS and CVD in rural Kazakh populations living in other countries, such as Kazakhstan and Uzbekistan owing to similarities in religion, culture, lifestyle, diet, and genetic background in these ethnic groups.

\section{Conclusions}

Elevated BP, elevated WC, and elevated TG are independent risk factors for CVD in Kazakhs. Therefore, it is important to control $\mathrm{BP}$, WC, and TG to prevention CVD in this population.

\section{Abbreviations \\ CVD: Cardiovascular disease; MS: Metabolic syndrome; CHD: Coronary heart disease; WC: Waist circumference; BP: Blood pressure; SBP: Systolic blood pressure; DBP: Diastolic blood pressure; FPG: Fasting plasma glucose; TG: Triglyceride; HDL-C: High density lipoprotein cholesterol; IERB: Institutional Ethics Review Board; WC (-): Without WC; BP(-): Without BP; TG(-): Without TG; WC (+): With WC; BP (+): With BP; TG (+): With TG; RERI: Relative excess risk due to interaction; AP: Attributable proportion due to interaction; SI: Synergy index; Cl: Confidence interval; HR: Hazard ratio}

\section{Acknowledgments}

We sincerely thank those who participated in the study. We would also like to thank the clinical laboratory of First Affiliated Hospital of Shihezi University School of Medicine for their test work.

\section{Authors' contributions}

We thank all the individuals who participated in the present study. S G,W Y, and $\mathrm{J} \mathrm{H}$ had the original idea for the study and all co-authors carried out the design. $H$ W, $Y L, X Z, Y H$, and $H G$ were responsible for recruitment and follow-up of study participants. $K W, Y Y, J Z, J M, L M$, and $L M$ were responsible for data cleaning, and J L, Y S,C L, Z M, R M carried out the analyses. W $\mathrm{Y}$ and $\mathrm{J} \mathrm{H}$ drafted the manuscript, which was revised by all authors. All authors read and approved the final manuscript.

\section{Funding}

This research was supported by grants from the National Natural Science Foundation of China (No. 81560551) and Shihezi University Youth Innovation and Cultivation Talent Project (No. CXPY202). The funder had no role in the design of the study, in the collection, analysis, and interpretation of the data, or in the writing or approval of the manuscript.

\section{Availability of data and materials}

The datasets used and analyzed during the current study are available from the corresponding author on reasonable request.

\section{Ethics approval and consent to participate}

This study was approved by the Institutional Ethics Review Board (IERB) of the First Affiliated Hospital of Shihezi University School of Medicine (IERB No.SHZ2010LL01). All participants signed informed consent forms before joining the study.

\section{Consent for publication \\ Not applicable.}

\section{Competing interests}

The authors declare that they have no competing interests.

Received: 9 June 2020 Accepted: 14 January 2021

Published online: 26 January 2021

\section{References}

1. He J, Gu D, Wu X, Reynolds K, Duan X, Yao C, et al. Major causes of death among men and women in China. N Engl J Med. 2005;353(11):1124-34.

2. Grundy SM, Cleeman JI, Daniels SR, Donato KA, Eckel RH, Franklin BA, et al. Diagnosis and management of the metabolic syndrome: an American Heart Association/National Heart, Lung, and Blood Institute scientific statement. Circulation. 2005;112(17):2735-52

3. Mottillo S, Filion KB, Genest J, Joseph L, Pilote L, Poirier P, et al. The metabolic syndrome and cardiovascular risk a systematic review and metaanalysis. J Am Coll Cardiol. 2010;56(14):1113-32.

4. Neil TG, Mary SC, Mcghee SM, Sai-Yin H, Cheung BMY, Wat NMS, et al. Thomas GN, schooling CM, McGhee SM, et al. metabolic syndrome increases all-cause and vascular mortality: the Hong Kong cardiovascular risk factor study. Clin Endocrinol. 2007;66(5):666-71.

5. Noda H, Iso H, Saito I, Konishi M, Inoue M, Tsugane S. The impact of the metabolic syndrome and its components on the incidence of ischemic heart disease and stroke: the Japan public health center-based study. Hypertension Res Official J Japanese Soc Hypertension. 2009;32(4):289-98.

6. Liu J, Grundy SM, Wang W, Jr SCS, Vega GL, Wu Z, et al. Ten-year risk of cardiovascular incidence related to diabetes, prediabetes, and the metabolic syndrome. Am Heart J. 2007;153(4):552-8.

7. Chien KL, Hsu HC, Sung FC, Su TC, Chen MF, Lee YT. Metabolic syndrome as a risk factor for coronary heart disease and stroke: an 11-year prospective cohort in Taiwan community. Atherosclerosis. 2007;194(1):214-21.

8. Guo H, Ru-Lin MA, Zhang JY, Rui DS, Shang-Zhi XU, Sun F. Comparative analysis of epidemic characteristic of metabolic syndrome of Kazakh and Hans in Xinjiang. Chinese J Hypertension. 2011;19(6):538-43.

9. Ru-Lin MA, Guo SX, Yan LI. Prevalence of dyslipidemia and its influencing factors in Kazakh adults. Chin J Public Health. 2012;28(8):1009-13.

10. He J, Guo H, Zhang JY, Ding YS, Liu JM, Zhang M, et al. Epidemiological study on overweight and obesity among rural adult residents in Hazakh and Uygur population in Xinjiang province, 2010. Zhonghua Yu Fang Yi Xue Za Zhi. 2013:47(10):954.

11. Organization WH. Obesity: preventing and managing the global epidemic. Report of a WHO consultation. World Health Organization technical report series. 2000;894(i-xii):1-253.

12. Yang WW, Gao X, Zhang XH, Hu YH, Guo H, Wang K, et al. Impact of interactions among metabolic syndrome components on the development of cardiovascular disease among Kazakhs in Xinjiang. PloS One. 2018;13(10): e0205703.

13. Lakka HM, Laaksonen DE, Lakka TA, Niskanen LK, Kumpusalo E, Tuomilehto J, et al. The metabolic syndrome and total and cardiovascular disease mortality in middle-aged men. JAMA. 2002;288(21):2709-16.

14. Third Report of the National Cholesterol Education Program (NCEP) Expert Panel on Detection, Evaluation, and Treatment of High Blood Cholesterol in 
Adults (Adult Treatment Panel III) final report. Circulation. 2002;106(25): 3143-421.

15. Dada AS, Ajayi DD, Areo PO, Raimi TH, Emmanuel EE, Odu OO, et al. Metabolic syndrome and Framingham risk score: observation from screening of low-income semi-urban African women. Medicines. 2016;3(2): 15.

16. Suh S, Baek J, Bae JC, Kim KN, Park MK, Kim DK, et al. Sex factors in the metabolic syndrome as a predictor of cardiovascular disease. Endocrinol Metab. 2014;29(4):522-9.

17. Forouzanfar MH, Moran AE, Flaxman AD, Roth G, Mensah GA, Ezzati M, et al. Assessing the global burden of ischemic heart disease, part 2: analytic methods and estimates of the global epidemiology of ischemic heart disease in 2010. Glob Heart. 2012;7(4):331-42.

18. Del Brutto OH, Mera RM, Montalvan M, Del Brutto VJ, Zambrano M, Santamaria M, et al. Cardiovascular health status and metabolic syndrome in Ecuadorian natives/mestizos aged 40 years or more with and without stroke and ischemic heart disease--an atahualpa project case-control nested study. J Stroke Cerebrovasc Dis. 2014;23(4):643-8.

19. Liu C, Liansheng R, Zheng H, Sun Z, Dai C. The association between the components of metabolic syndrome and cardiovascular diseases. Chinese Journal of Clinical Healthcare. 2016

20. Guo L, Hu XS, Guo ZR, Kang GD, Wu M, Zhou H. Association and interaction between the components of metabolic syndrome and cardiovascular disease. Zhonghua Xin Xue Guan Bing Za Zhi. 2009;37(7):644.

21. Ninomiya T, Kubo M, Doi Y, Yonemoto K, Tanizaki Y, Rahman M, et al. Impact of metabolic syndrome on the development of cardiovascular disease in a general Japanese population: the Hisayama study. Stroke. 2007; 38(7):2063-9.

22. Khang YH, Cho SI, Kim HR. Risks for cardiovascular disease, stroke, ischaemic heart disease, and diabetes mellitus associated with the metabolic syndrome using the new harmonised definition: findings from nationally representative longitudinal data from an Asian population. Atherosclerosis. 2010;213(2):579-85.

23. Mcneill AM, Rosamond WD, Girman CJ, Golden SH, Schmidt MI, East HE, et al. The metabolic syndrome and 11-year risk of incident cardiovascular disease in the atherosclerosis risk in communities study. Diabetes Care. 2005;28(2):385-90

24. Sattar N, Gaw A, Scherbakova O, Ford I, O'Reilly DS, Haffner SM, et al. Metabolic syndrome with and without C-reactive protein as a predictor of coronary heart disease and diabetes in the west of Scotland coronary prevention study. Circulation. 2003;108(4):414-9.

25. Martiniuk AL, Lee CM, Lawes CM, Ueshima H, Suh I, Lam TH, et al. Hypertension: its prevalence and population-attributable fraction for mortality from cardiovascular disease in the Asia-Pacific region. J Hypertens. 2007;25(1):73-9.

26. Kadota A, Hozawa A, Okamura T, Kadowak T, Nakmaura K, Murakami Y, et al. Relationship between metabolic risk factor clustering and cardiovascular mortality stratified by high blood glucose and obesity: NIPPON DATA90, 1990-2000. Diabetes Care. 2007:30(6):1533-8.

27. Shin CY, Yun KE, Park HS. Blood pressure has a greater impact on cardiovascular mortality than other components of metabolic syndrome in Koreans. Atherosclerosis. 2009;205(2):614-9.

28. Alexander CM, Landsman PB, Teutsch SM, Haffner SM. NCEP-defined metabolic syndrome, diabetes, and prevalence of coronary heart disease among NHANES III participants age 50 years and older. Diabetes. 2003;52(5): $1210-4$.

29. Hadaegh F, Zabetian A, Khalili D, Safarkhani M, Philip TJW, Azizi F. A new approach to compare the predictive power of metabolic syndrome defined by a joint interim statement versus its components for incident cardiovascular disease in Middle East Caucasian residents in Tehran. J Epidemiol Community Health. 2012;66(5):427-32.

30. Alexander RW. Theodore Cooper memorial lecture. Hypertension and the pathogenesis of atherosclerosis. Oxidative stress and the mediation of arterial inflammatory response: a new perspective. Hypertension. 1995;25(2): $155-61$.

31. Reiner Ž. Hypertriglyceridaemia and risk of coronary artery disease. Nat Rev Cardiol. 2017;14(7):401-11.

32. Nordestgaard BG, Varbo A. Triglycerides and cardiovascular disease. Lancet. 2014;384(9943):626-35.

33. Alaupovic P, Mack WJ, Knightgibson C, Hodis HN. The role of triglyceride-rich lipoprotein families in the progression of atherosclerotic lesions as determined by sequential coronary angiography from a controlled clinical trial. Arterioscler Thromb Vasc Biol. 1997;17(4):715-22.

34. Shen W. Total body skeletal muscle and adipose tissue volumes: estimation from a single abdominal cross-sectional image. J Appl Physiol. 2004;97(6): 2333-8.

35. Yu W, Bai B. Research progress in the relationship between adipokines and obesitylinked cardiovascular disease. Chin Heart J. 2016;3:344-7.

36. Sundstrom J, Riserus U, Byberg L, Zethelius B, Lithell H, Lind L. Clinical value of the metabolic syndrome for long term prediction of total and cardiovascular mortality: prospective, population based cohort study. BMJ. 2006;332(7546):878-82.

\section{Publisher's Note}

Springer Nature remains neutral with regard to jurisdictional claims in published maps and institutional affiliations.
Ready to submit your research? Choose BMC and benefit from:

- fast, convenient online submission

- thorough peer review by experienced researchers in your field

- rapid publication on acceptance

- support for research data, including large and complex data types

- gold Open Access which fosters wider collaboration and increased citations

- maximum visibility for your research: over $100 \mathrm{M}$ website views per year

At $\mathrm{BMC}$, research is always in progress.

Learn more biomedcentral.com/submissions 